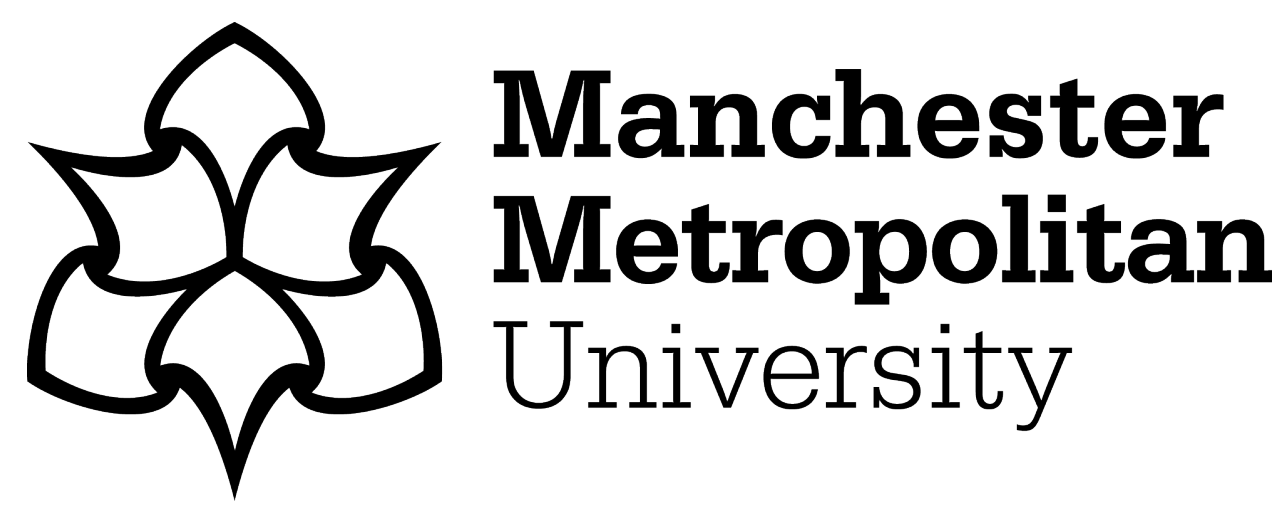

Jung, T, Lee, H, Chung, N and tom Dieck, Mandy (2018) Cross-Cultural Differences in Adopting Mobile Augmented Reality at Cultural Heritage Tourism Sites. International Journal of Contemporary Hospitality Management, 30 (3). pp. 1621-1645. ISSN 0959-6119

Downloaded from: https://e-space.mmu.ac.uk/619134/

Version: Accepted Version

Publisher: Emerald

DOI: https://doi.org/10.1108/IJCHM-02-2017-0084

Please cite the published version 
Please cite as: Jung, T., Lee, H., Chung, N. \& tom Dieck, M.C. (2018). Cross-Cultural Differences in Adopting Mobile Augmented Reality at Cultural Heritage Tourism Sites. International Journal of Contemporary Hospitality Management. 30(8).

\title{
Cross-Cultural Differences in Adopting Mobile Augmented Reality at Cultural Heritage Tourism Sites
}

\author{
Purpose \\ Augmented reality (AR) is increasingly used in cultural heritage tourism sites for the enhancement of \\ the tourist experience. However, behavioral intention to adopt AR is dependent on cultural traits and \\ close investigation is required on cultural differences. To explore these cultural differences and the \\ effect on AR acceptance in cultural heritage tourism sites, the current study focused on the aesthetic \\ and hedonic characteristics of AR applications.
}

\section{Design/methodology/approach}

Data were collected in two countries with strong contrasts in Hofstede's cultural dimensions to explore cultural differences in AR acceptance. In total, 145 questionnaires were collected in Deoksugung Palace, South Korea, and 119 questionnaires were collected in the An Post Museum, Republic of Ireland. Data were analyzed using PLS Graph 3.0.

\section{Findings}

The findings confirmed that the aesthetics of AR have a strong influence on perceived enjoyment. Furthermore, this study supported the notion that high-power distance, collectivism and high uncertainty avoidance culture such as South Korea's perceives stronger dependence on social influence and the hedonic characteristics of AR.

\section{Practical Implications}

AR innovation and marketing within the hospitality and tourism industry requires an understanding of cultural differences to ensure successful implementation. In addition, tourism and hospitality managers need to ensure that the needs and requirements of different target markets are met.

\section{Originality/value}

This study applied Hofstede's cultural dimensions to explore the differences between two very distinct countries with regard to AR acceptance. The findings provide important implications for the implementation of tourism AR applications for different countries, especially considering international target markets.

Keywords: augmented reality, cross-cultural analysis, acceptance, cultural heritage tourism sites 


\section{Introduction}

Applications such as Pokémon Go (http://www.pokemongo.com) have led to an increased awareness, interest and use of augmented reality (AR) for everyday uses (Rauschnabel et al., 2017). The overlay of digital information onto users' direct surroundings provides opportunities for various industries including the enhancement of the tourism experience (tom Dieck and Jung, 2015). The recent success and emergence of AR can be directly linked to the penetration of smartphones, which in turn have long been considered for mediating tourist experiences (Wang et al., 2012). According to numerous scholars, cultural heritage tourism has grown to become one of the dominant tourism sectors served by mobile AR applications (Portalés et al., 2009; Tutunea, 2013). Within the cultural heritage tourism context, AR can be used to digitally restore artifacts or re-create historic events while at the same time preventing the degradation of cultural heritage sites (Haugstvedt \& Krogstie, 2012; Portalés et al., 2009; Stanco et al., 2012). Overall, AR applications were found to create enjoyable, meaningful and enhanced tourism experiences (Jung et al., 2015). Over the last five years, a number of cultural heritage institutions (e.g., Deoksugung and Gyeongbokgung Palaces in Seoul, An Post Museum in Dublin, the Louvre, the British Museum) all over the world have developed and implemented mobile AR applications.

Research on AR has expanded over the past years, with scholars' interests including user acceptance (Jung et al., 2015), user experience (Han et al., 2017), user requirements (tom Dieck et al., 2016), perceived value (tom Dieck \& Jung, 2017), value co-creation (Jung \& tom Dieck, 2017), wearable augmented reality (Rauschnabel et al., 2015, Tussyadiah et al., 2017) and the tourism learning experience (Moorhouse et al., 2016). However, there are only a few studies within the hospitality context, and those that exist have focused on AR's navigation opportunities and finding points of interest such as hotels and restaurants (Marimon et al., 2010; Mulloni et al., 2010). Tuominen and Ascencao (2016) looked at tomorrow's hotel and explored new technologies and their effect on service design. However, although they acknowledge that the future hotel room will include augmented experiences, a specific investigation of AR was not conducted. Augment (2016, p. 1) posted about AR opportunities for the hotel industry stating, "hoteliers can easily offer prospective guests the experience of visualizing the property, exploring individual rooms, and searching for nearby attractions in an immersing and interactive manner." This insight clearly shows the marketing and customer relationship management opportunities of AR for the hospitality industry.

Although various AR applications have been widely implemented, cultural differences are recognized as influencing the acceptance of technology in general and AR in particular (Harris et al., 2005). Nevertheless, AR-related research on cultural differences is limited. A number of prior studies (Cho \& Cheon, 2005; Harris et al., 2005; Kim et al., 2011) have shown that the process of generating behavioral intentions to use technologies varies among cultures. These studies have selected several countries with a similar level of social or technological development but very different cultural profiles. For example, Korea and Japan, and the United States and the United Kingdom were chosen in a study by Cho and Cheon (2005) as countries having strong advertising revenues in Eastern and Western cultures, respectively, yet with completely different cultural profiles.

One study by Han et al. (2009) explored the acceptance of tutoring robots with augmented reality services and revealed that there are cultural differences among Western and Eastern users. For instance, they found that Europeans considered robots simply as machines, whereas Asians believed robots to be their friends. This was confirmed by Harris et al. (2005) who stated that the strength of the relationship among the beliefs, social influence, and intention to use AR can differ from culture to culture. Further, Balog and Pribeanu (2010) revealed that generalizability of AR acceptance studies is always limited due to a lack in focus on cultural differences. Overall, these examples show that AR 
plays an increasingly important role for future society with new technological developments (e.g., robots); however, acceptance seems to be clearly linked to cultural traits.

Nevertheless, little is known about how cultural traits influence AR acceptance. Thus, this study aimed to explore the cultural differences in AR adoption. The first objective of this study was to explore the effects of aesthetics and perceived attributes, including enjoyment, on behavioral intention to use AR in cultural heritage tourism sites. Also, this study examined the aesthetics of AR, a construct originally proposed in the Experience Economy concept by Pine and Gilmore (1998). The second objective of this study was to investigate the influence of cultural differences between South Korea and Ireland on these causal sequences. Further, the motivational theory by Deci (1975) and the technology acceptance model by Davis (1989) were used to investigate the enjoyment of AR. In this regard, the present study investigated the cultural difference index values of the top 15 countries with the highest smartphone penetration rate in the first quarter of 2013. Among them, Ireland and South Korea were found to be farthest from each other from the cultural viewpoint. Therefore, these two countries were selected to explore how differences in culture may influence beliefs and intention to use AR applications by drawing upon the cultural difference dimensions proposed by Hofstede (1980). Furthermore, the current study focuses on the aesthetics and enjoyment of AR application from the perspective of the hedonic information system.

\section{Theoretical Background}

\section{Aesthetic and Hedonic Features of Augmented Reality}

AR is the digital overlay of computer-generated content into users' direct field of vision, thus creating the illusion of virtual and real objects coexisting in the same space (tom Dieck \& Jung, 2015). Consequently, AR not only enhances the real environment, but also users' cognitive capability toward their surroundings in real time, as shown in Figure 1 (Bujak et al., 2013).

\section{Insert Figure 1 about here}

The nature of AR allows tourists to immerse themselves in a virtually enhanced real environment (Di Serio et al., 2013). According to Pine and Gilmore (1998, p. 31), immersion can be defined as "becoming physically or virtually a part of the experience itself." Pine and Gilmore (1998) furthermore proposed the four realms of the experience economy, which are entertainment, education, aesthetics and escapism. In the present study, we were particularly interested in aesthetic experiences, which have been defined as being "indulged in environments" (Oh et al., 2007, p. 121) and features consumers' passive participation and immersion. Taking these definitions into account, tourists who use the AR application at cultural heritage tourism sites only passively participate in activities that do not directly affect or influence the performance while being immersed in the experience. In particular, aesthetics play an important role in application-based AR applications (Wang et al., 2012) as smartphones have physical constraints (e.g., smaller displays with lower resolution than traditional devices) (Sadeh, 2003). Thus, it is important to design mobile applications by taking into account smartphone capabilities to ensure that information and content is delivered accurately and clearly (Lee \& Chung, 2009).

This study also focused on both the hedonic and utilitarian features of AR using Deci's (1975) motivational theory. Motivational theory proposes that user adoption of a service or product should be effected and explained by extrinsic and intrinsic motivations (Deci, 1975). Within information technology usage, according to Deci and Ryan (1987), extrinsic motivations are concerned with the drive of the utilitarian purpose, such as receiving rewards or benefits and rationally analyzing functions. On the other hand, intrinsic motivations relate to the drive of hedonic purposes, including the expectation of pleasure, satisfaction and overall delight (Vallerand, 1997; Van der Heijden, 2004). 
Perceived usefulness, ease of use and enjoyment are among the principal constructs of technology acceptance studies to predict users' attitudes and behavioral intentions (Davis, 1989; Kim et al., 2009; Van der Heijden, 2004). While perceived usefulness and ease of use focus on extrinsic motivation, perceived enjoyment is related to intrinsic motivation (Ayeh et al., 2013; Van der Heijden, 2004). Numerous studies have investigated the relationship between perceived attributes of AR, attitudes and behavioral intentions. However, most have considered only the utilitarian components of AR, such as perceived usefulness and ease of use (e.g., Vlahakis et al., 2001); only a few attempts have been made to investigate the hedonic components of AR. Therefore, the present study investigated extrinsic and intrinsic motivations and their influence on the behavioral intention to use AR in cultural heritage tourism sites.

\section{Cultural Differences}

In tourism research, cross-cultural differences have been perceived as significant because tourists' cultural background is related to the experience they seek. Thus, investigating cultural differences among tourists is regarded as the basis for any successful marketing strategy (Landauer et al., 2013). The tourism industry, combined with IT, is becoming more and more international (Li, 2012) and facing an increasing number of inbound tourists from different cultures (Tsang \& Ap, 2007). According to Lee (2013), cultural differences are often considered a barrier to technology transfer and Harris et al. (2005) supported the idea that information system acceptance is largely influenced by culture. In particular, AR is strongly affected by culture-level phenomena because it features interactions and operates as part of a network and, therefore, a cross-cultural approach on IT acceptance is required and necessary (Di Serio et al., 2013; Harris et al., 2005). This study drew on Hofstede's (1980) cultural dimensions to explore the influence of cultural differences on AR acceptance in Ireland and South Korea. Hofstede (1980) defined culture as "the collective programming of the mind which distinguishes the members of one human group from another" ( $p$. 260). Furthermore, Hofstede (1980) suggested the four cultural dimensions (long-term orientation was subsequently added by Hofstede and Bond, 1988) through which countries are comparable: masculinity/femininity; power distance; individualism/collectivism; and uncertainty avoidance. Definitions of these dimensions are displayed in Table 1.

As discussed previously and presented in Table 1, South Korean culture has characteristics of femininity, high power distance, collectivism and high uncertainty avoidance while Ireland culture has masculinity, low power distance, individualism and low uncertainty avoidance. South Korea and Ireland have high smartphone penetration rates, ranking second $(73.0 \%)$ and eleventh $(57.0 \%)$, respectively worldwide (Richter, 2013). In addition, both countries have launched AR applications in cultural heritage tourism sites. In South Korea, AR applications have been developed for cultural heritage sites by government organizations, such as the Korea Tourism Organization, the Ministry of Science, ICT and Future Planning, and the Culture Heritage Administration. Deoksugung Palace, one of the royal palaces in Korea, launched a mobile application called "Deoksugung, in my hands," which contains 1,634 items such as pictures, videos and 3D images related to the palace and nearby points of interest through AR (http://visitkorea.or.kr). In Ireland, the "Dublin AR" application, which contains text, pictures and video, was developed for the An Post Museum, one of the historic buildings along Dublin's independence trail. The project was initiated to create awareness and enhance the tourist experience in the context of Dublin's historical heritage (tom Dieck \& Jung, 2015).

\section{Insert Table 1 about here}




\section{Hypothesis Development}

To explore the cultural differences between the two countries of this study, South Korea and Ireland, we proposed the conceptual model displayed in Figure 2.

\section{Insert Figure 2 about here}

\section{Aesthetics and Beliefs}

As discussed previously, aesthetic experiences are defined as being "indulged in environment" and feature consumers' passive participation and immersion (Pine \& Gilmore, 1998; Oh et al., 2007). This study adopted the theoretical framework from Cyr et al. (2006) and Li and Yeh (2010), both exploring the mobile context with regards to mobile loyalty and mobile trust, respectively. These studies found that aesthetics is a crucial component of Pine and Gilmore's (1998) Experience Economy that needs to be explored within the mobile context. In particular, Cyr et al. (2006) suggested that aesthetics and beautiful interface design determines whether users decide to use and continue to use a technology. Also, Cyr et al. (2006) and Li and Yeh (2010) revealed that aesthetics influence the perceived usefulness, ease of use and enjoyment of technological innovations. Due to the nature of the technology, AR provides tourists with an aesthetic experience in which they passively engage and immerse themselves in a virtually enhanced environment (Di Serio et al., 2013; Billinghurst et al., 2001). Overall, aesthetics represents the beauty that can be portrayed through elements such as layout, font, color or photographs. Although the screen size and resolution of smartphones has increased over the years, there are still constraints in terms of providing or receiving content. Nevertheless, these physical constraints can be overcome by the beauty of information systems (Sarker \& Wells, 2003). Consequently, initial feelings and impressions based on the aesthetic aspects can lead users to positively judge the usefulness or joyfulness of the product. Furthermore, a well-designed AR application can aid in the accurate and clear delivery of content and information. This was supported by MacDonald and Atwood (2014), who found that aesthetic perceptions are highly related to usability. In addition, the aesthetics of information systems have been confirmed to have an effect on inducing positive beliefs, including perceived usefulness, ease of use and enjoyment (Cyr et al., 2006; Li \& Yeh, 2010). Therefore, we propose that the aesthetics of AR influence cognitive and affective beliefs of an AR application:

$H_{l}$ : The aesthetics of AR have a positive impact on the perceived usefulness of AR.

$\mathrm{H}_{2}$ : The aesthetics of AR have a positive impact on the perceived ease of use of AR.

$H_{3}$ : The aesthetics of AR have a positive impact on the perceived enjoyment of AR.

\section{Relationships among Perceived Usefulness, Perceived Ease of Use and Perceived Enjoyment}

Perceived usefulness, perceived ease of use and perceived enjoyment are three principal constructs of technology acceptance model research and were found to predict users' behavioral intention (Davis, 1989). Many studies have confirmed the importance of ease of use and its strong effect on perceived usefulness (Davis, 1989; Haugstvedt \& Krogstie, 2012; Kim et al., 2009; Van der Heijden, 2004). More recently, Haugstvedt and Krogstie (2012) explored the paths between the perceived ease of use and usefulness and behavioral intention to use mobile AR in the context of cultural heritage. A similar finding was made by Chuah et al. (2016) within the wearable smartwatch adoption context. These results found that perceived ease of use strongly influences perceived usefulness, enjoyment and behavioral intentions (Haugstvedt \& Krogstie, 2012). Solomon (2009) suggested that, as part of experiences, individuals act according to their emotional status, and, therefore, affective factors (e.g., perceived enjoyment) induce cognitive factors (e.g., perceived ease of use). With regard to the intention to use information systems, several studies have investigated perceived enjoyment. For instance, Ayeh et al. (2013) and tom Dieck et al. (2017) demonstrated that perceived enjoyment strongly affects perceived usefulness, ease of use, attitude and intention to use social media for travel 
planning. In fact, perceived enjoyment was found to be a strong determinant of ease of use within a variety of studies and contexts (e.g., Venkatesh, 2000; Venkatesh \& Bala, 2008). Therefore, this study suggests that:

$H_{4}$ : The perceived ease of use of AR has a positive impact on the perceived usefulness of AR.

$H_{5}$ : The perceived enjoyment of AR has a positive impact on the perceived ease of use of AR.

\section{Influencing Factors of Behavioral Intention to Use AR}

Deci (1975) developed the motivational theory and found that behavioral intention to use information systems can be explained by extrinsic and intrinsic motivations. On the one hand, utilitarian consumers are said to be more motivated extrinsically and use technology for their work while expecting rewards or benefits in return. On the other hand, hedonic consumers are revealed to be intrinsically motivated by expecting benefits with regards to fun, enjoyment and sensory stimulation (Chun et al., 2012; Van der Heijden, 2004). Taking motivational theory into consideration, this study incorporated both utilitarian and hedonic features of AR.

First, this study adopted three beliefs of the technology acceptance model: perceived usefulness, ease of use and enjoyment. Perceived usefulness and ease of use focus on extrinsic motivation, while enjoyment focuses on intrinsic motivation (Ayeh et al., 2013; Van der Heijden, 2004). According to Davis (1989), these beliefs are principal determinants of users' attitudes and behavioral intentions. In addition, the effect of enjoyment on behavioral intentions has been supported by numerous technology acceptance studies (e.g., Gao \& Bai, 2014; Lu \& Su, 2009). Within the internet of things and mobile shopping context, the two aforementioned studies found that enjoyment, as an intrinsic motivation, has high implications for the intention to use technology.

Second, social influence is "the degree to which an individual perceives that important others believe he or she should use the new system" and another determinant of behavioral intentions (Venkatesh et al., 2003, p. 451). According to Venkatesh et al. (2003), social influence tends to be important only in the early stage of a users' experience in mandatory/work settings. The effect of perceived usefulness and ease of use on behavioral intentions has been well established and supported from the majority of technology acceptance researchers (e.g., Chuah et al., 2016; Davis, 1989; tom Dieck et al., 2017). Although AR applications investigated are spontaneously and voluntarily used by tourists, this study added social influence as an independent construct to investigate the influence of social influence on the behavioral intention to use AR. This concurs with previous research that confirmed the importance of social influence in the voluntary digital tourism (tom Dieck et al., 2017) and Internet of Things (Gao and Bai, 2014) context. Therefore, the following hypotheses are proposed:

$H_{6}$ : The perceived usefulness of AR has a positive impact on the behavioral intention to use AR.

$H_{7}$ : The perceived ease of use of AR has a positive impact on the behavioral intention to use AR.

$H_{8}$ : The perceived enjoyment of AR has a positive impact on the behavioral intention to use AR.

$H_{9}$ : Social influence has a positive impact on the behavioral intention to use AR.

\section{Cultural Differences in South Korea's and Ireland's Intention to Use AR \\ Masculinity/Femininity}

According to Hofstede (1984), countries are differentiated by the psychological genders that the societies espouse, namely, masculinity and femininity. To summarize a masculine culture, values are placed on work goals, assertiveness and material success. On the contrary, feminine cultures place their values on quality-of-life goals, nurturing and modesty (Hofstede, 1998). Linking this to the literature discussed above, instrumental values such as perceived usefulness are considered masculine values, whereas ease of use is concerned with the creation of a pleasant environment (Venkatesh et al., 
2003; Venkatesh \& Morris, 2000). Considering that perceived usefulness is related to the enhancement of job performance, it is expected that this would receive more intention in a masculine culture, which focuses on work goals and success. On the other hand, in a feminine culture, users tend to place more importance on technology support staff (Venkatesh \& Morris, 2000). Placing this into the context of the present study, which is interested in the cultural differences of two countries, South Korea has a feminine culture, while Ireland has a masculine culture (see Table 1).

McCoy et al. (2007) conducted a study on cultural differences revealing that the effect of perceived usefulness on behavioral intentions is significant within both masculine and feminine cultures. However, they further revealed that perceived ease of use was only significant within feminine cultures. This is supported by a number of scholars (Srite and Karahanna, 2006; Tarhin et al., 2017) with Tarhini et al. (2017, p. 312) proposing and confirming that perceived ease of use "will be more important for users who espouse feminine values since feminine cultures tend to emphasize the creation of more pleasant work environments." Consequently, masculine cultures were thought to be more concerned with accomplishing goals than with usability issues (McCoy et al., 2007). Therefore, it can be hypothesized that Irish users tend to focus on the usefulness of AR, while South Koreans tend to focus on the ease of use of AR. Therefore, we propose $\mathrm{H}_{6 \mathrm{a}}, \mathrm{H}_{7 \mathrm{a}}$.

$H_{6 a}$ : The relationship between perceived usefulness and behavioral intention to use AR will be weaker in South Korea than Ireland.

$H_{7 a}$ : The relationship between perceived ease of use and behavioral intention to use AR will be stronger in South Korea than Ireland

\section{Power distance}

According to Hofstede (1984), the cultural dimension of power distance can be explained as the degree to which power and specifically inequality is accepted by individuals of a society. Power distance is regarded as the most relevant dimension among the four cultural dimensions used to explain the impact of cultural difference on perceptions of service provision (Tsang \& Ap, 2007). In higher power distance cultures, individuals tend to accept that superiors have more power and thus employees take the status quo for granted. This can result in individuals being more relaxed and fun-loving compared to those in lower power distance cultures which are argued to induce a greater demand for hedonic services (Harris et al., 2005). Findings of Harris et al.'s (2005) research revealed that respondents in a higher power distance country had more positive attitudes to hedonic services than respondents in a lower power distance culture. Furthermore, social influence is another important factor in higher power distance cultures as it relates to compliance and the desire to gain favorable reactions from superiors (Kelman, 1958; Kelman, 1961; Srite \& Karahanna, 2006).

As discussed above, there are a number of studies that confirm the effect of enjoyment and social influence on behavioral intentions (Gao \& Bai, 2014; tom Dieck et al., 2017). In addition, power distance has been established as an important cultural dimension for technology acceptance research (McCoy et al., 2007). However, to the best of our knowledge, there has not been any research exploring the role of power distance within the relationship of enjoyment and social media on behavioral intentions. In order to bridge the gap in the literature, we propose $\mathrm{H}_{8 \mathrm{a}}$.

$H_{8 a}$ : The relationship between perceived enjoyment and behavioral intention to use AR will be stronger in South Korea than Ireland. 


\section{Individualism/Collectivism and uncertainty avoidance}

Another cultural dimension links to the differences between individualist and collectivist cultures. According to this differentiation, people from an individualist culture tend to be concerned with and motivated by personal preferences or needs, acting according to their own attitude. On the other hand, collectivist cultures lean more toward a socially appropriate manner and aim to conform to others in the group (Triandis, 1995). This was confirmed by Rohm et al.'s (2012) findings that the need for social recognition is much more prominent in Western individualist cultures compared to collectivism. Taking these differentiations into consideration, it is assumed that word-of-mouth communication and social influence are stronger in a collectivist culture (Harris et al., 2005). Therefore, in the context of AR, people in a collectivist culture such as South Korea are more likely to decide to use AR at cultural heritage tourism sites based on the influence of friends and family.

Furthermore, a lack of information is expected to make people nervous and perceive a task as risky (Baird \& Thomas, 1985; Vitell et al., 1993). Therefore, in the context of AR, informational and normative influence is considered critical. Previous studies have revealed that informational and normative influence reduces uncertainty about whether the usage of technology is appropriate (Evaristo \& Karahanna, 1998; Srite \& Karahanna, 2006). In a recent study, Tarhin et al. (2017) found that the effect of social influence on behavioral intentions is more important within the Korean collectivist culture than in the United States which has an individualist culture). Consequently, it can be surmised that social influence will have a stronger effect on AR usage in collectivist cultures than in individualist cultures. This was further confirmed by a study on mobile marketing (Rohm et al., 2012), which found that social attachment is immensely important in collectivist countries. Therefore, we propose $\mathrm{H}_{9 \mathrm{a}}$.

$H_{9 a}$ : The relationship between social influence and behavioral intention to use AR will be stronger in South Korea than Ireland.

\section{Research Methods}

\section{Data Collection}

The surveys were administered at Deoksugung Palace in South Korea and the An Post Museum in Ireland. To examine the impact of cultural differences on behavioral intentions to use AR more accurately, the same AR applications should be used. However, in reality, it is difficult to develop two AR applications with the exact same contents and functions due to the different levels of technological advances in different countries, as well as the different contents and functions according to the different purposes of the applications and different cultural contexts. However, the two applications used in this study have comparatively similar functionalities in terms of structure, design and interface as well as the role of providing their users with historic information and enjoyment at the same time.

Since we considered that most visitors were not aware of the application, we provided visitors with printed material explaining AR in general and how to use the AR apps in the sites. This material helped participants familiarize themselves with the app before participating in the survey, and allow them to evaluate the application more accurately. In Seoul, we provided visitors with printed material in front of the gate of Deoksugung on November 16, 2013, and let them use AR apps in the three major palace buildings of Deoksugung (i.e., Junghwajeon, Hamnyungjeon and Seogeodang). Only visitors who had previously used AR apps were allowed to participate in this survey. Gift certificates worth KRW 5,000 (about USD 5) were given to them. In Dublin, a similar approach was followed and visitors were provided with a map highlighting AR-enabled content in and around the An Post Museum. Also, only visitors who had previously used AR applications participated in the study. 
Prior to participating in the survey, randomly selected visitors used the AR applications in Deoksugung Palace and the An Post Museum for about thirty minutes. In total, 145 questionnaires were collected in Deoksugung Palace and 119 questionnaires were collected in the An Post Museum. Among all respondents at Deoksugung Place, 94 (64.8\%) were female, and 51 (35.2\%) were male; about half of the respondents were between 20 and 29 (46.2\%) or students (60.0\%). At the An Post Museum, 136 questionnaires were initially collected, and 17 were eliminated due to missing data. Among the 119 total respondents, 98 (82.4\%) were female, and 21 (17.6\%) were male; most respondents were younger than $29(92.4 \%)$ or students $(89.9 \%)$. Although the respondents to both surveys were young and highly educated, only $48(33.1 \%)$ in Korea and 11 (9.1\%) in Ireland had ever used AR before (see Table 2).

\section{Insert Table 2 about here}

\section{Measures}

Measurement items were adopted and modified from previous literature: aesthetics (Oh et al., 2007; Wang et al., 2012), perceived usefulness (Haugstvedt \& Krogstie, 2012; Venkatesh et al., 2003), perceived ease of use (Haugstvedt \& Krogstie, 2012; Venkatesh et al., 2003), perceived enjoyment (Gao \& Bai, 2014; Van der Heijden, 2004), social influence (Venkatesh et al., 2003), and behavior intention to use AR (Davis, 1989; Venkatesh et al., 2003). Items were tested using a seven-point Likert scale, ranging from strongly disagree (1) to strongly agree (7). This procedure resulted in 24 measurement items as part of the following constructs: aesthetics, perceived usefulness, perceived ease of use, perceived enjoyment, social influence, and behavioral intention to use AR. The same questionnaire was distributed in South Korea and Ireland. The questionnaire was initially created in English and then translated into Korean by individuals proficient in both languages to collect data at Deoksugung Palace in South Korea. Professors as well as researchers fluent in English and Korean with an academic specialization in the area under investigation then compared the translated version with the original version to ensure consistency. This process in the pretest phase confirmed that all questions were reliable and valid.

\section{Analysis and Results}

Partial least squares (PLS) regression analysis, using PLS-Graph Version 3.0, was used to test the proposed research model and compare the two countries for cultural differences. According to Ahuja and Thatcher (2005), relatively small sample sizes and few assumptions about the measurement scale and normal distribution are just a few of the advantages of this regression analysis. Before conducting any analysis, we first calculated the constructs' skewness and kurtosis of South Korea and Ireland (see Tables 4) to check their normality (Tabachnick \& Fidell, 2007). Skewness ranged from -1.371 to 0.282 in South Korea and from -0.815 to -0.117 in Ireland. Kurtosis values ranged from -0.335 to 2.330 in South Korea and from -0.331 to 0.179 in Ireland. Considering that the items were approximately normally distributed, we estimated the measurement and structural model.

\section{Measurement Model}

Self-reported data on two or more variables collected from the same source have the potential to lead to common method variance. Therefore, Harman's single-factor test is used to test for such bias (Lee et al., 2013; Podsakoff et al., 2003). This test assumes that, if a high level of common method variance is present, then when all the variables are entered together, they will load onto one factor, accounting for a majority of the variance. The exploratory factor analysis resulted in six factors with eigenvalues greater than one (see Table 3). There were no indications that the single-factor structure accounted for most of the variance, and therefore common method bias was not a concern.

\section{Insert Table 3 about here}


To validate the measurement model in this study, validity assessments of content, convergent and discriminant validity were conducted. First, the content validity of the survey was established from existing literature, and the measurement items were formulated by adopting constructs previously validated by other researchers. Second, convergent validity was ensured and established by examining composite reliability (CR), Cronbach's alpha and the average variance extracted (AVE) (Bhattacherjee \& Sanford 2006). Cronbach's alpha (greater than 0.5), CR (greater than 0.7), and AVE (greater than $0.5)$ were confirmed within both data sets and, thus, indicated that all the constructs used in this research model satisfied the requirements (see Table 3 ). Therefore, convergent validity was confirmed (Campbell \& Fiske, 1959; Fornell \& Larcker, 1981; Nunnally, 1967).

Discriminant validity is assessed by determining whether (1) the indicators load highly on their own theoretically assigned factors and not highly on other factors, and (2) the constructs share more variance with their own measures than they share with other constructs in the model. In variance analysis, the square root of every AVE is much larger than any correlation among any pair of latent constructs (see Table 4). Discriminant validity was thus supported herein (Chung et al., 2014; Bhattacherjee \& Sanford, 2006). Thus, the discriminant validity of the instrument was confirmed.

\section{Insert Table 4 about here}

\section{Structural Model: Main effects}

We estimated three separate models in PLS: models for the overall country, South Korea, and Ireland. To evaluate the $\mathrm{H}_{1} \sim \mathrm{H}_{9}$, overall country data was used, and to examine differences in the coefficients of $\mathrm{H}_{6 \mathrm{a}} \sim \mathrm{H}_{9 \mathrm{a}}$, we conducted a multigroup analysis. The size of the bootstrapping sample used was 500 . Table 5(a) displays the results of the hypothesis testing of the overall country sample. The result shows us all path coefficients were significant. Perceived usefulness was predicted by aesthetics of AR $(\beta=$ $0.393, p<0.001)$ and perceived ease of use $(\beta=0.368, p<0.001)$ which explained $43.6 \%$ of perceived usefulness variance. Hence, $\mathrm{H}_{1}$ and $\mathrm{H}_{4}$ were supported. Perceived ease of use was predicted by aesthetics of $\operatorname{AR}(\beta=0.140, p<0.05)$ and perceived enjoyment $(\beta=0.566, p<0.001)$, which explained $44.3 \%$ of perceived ease of use variance. Therefore, $\mathrm{H}_{2}$ and $\mathrm{H}_{5}$ were supported. Perceived enjoyment was predicted by aesthetics of $\operatorname{AR}(\beta=0.649, p<0.001)$, which explained $42.1 \%$ of perceived enjoyment variance. Thus, $\mathrm{H}_{3}$ was also supported. Behavioral intention was predicted by perceived usefulness $(\beta=0.209, p<0.01)$, perceived ease of use $(\beta=0.202, p<0.01)$, perceived enjoyment $(\beta=0.319, p<0.001)$ and social influence $(\beta=0.179, p<0.001)$. These four significant predictors explained $55.5 \%$ of the variance of behavioral intention to use AR. Therefore, $\mathrm{H}_{6} \sim \mathrm{H}_{9}$ were all supported.

\section{Structural Model: Moderating effects}

We present the moderating effect of cultural differences in Figure 2; we also analyze the remaining hypotheses, $\mathrm{H}_{6 \mathrm{a}}$ to $\mathrm{H}_{9 \mathrm{a}}$. To compare the research model cross-cultural differences group, we conducted a multigroup analysis using PLS by comparing differences in the coefficients of the corresponding structural paths of the two research models (Chin, 1998). The results indicate that the coefficients from each path among perceived usefulness, perceived ease of use, perceived enjoyment, social influence and behavioral intention to use AR for South Korea and Ireland are mostly significantly different from their corresponding coefficients in the structural model (see Table 5(b)).

\section{Insert Table 5 about here}

Hypotheses $\mathrm{H}_{6 \mathrm{a}}$ and $\mathrm{H}_{7 \mathrm{a}}$ focused on the impact of masculine and feminine culture on the relationship between beliefs (perceived usefulness and ease of use) and behavioral intention. Findings indicated 
that the relationship between perceived usefulness and behavioral intention to use AR was not stronger in Ireland's masculine culture than in South Korea's feminine culture. In the case of perceived usefulness, South Korea had a stronger effect on behavioral intentions compared to Ireland (South Korea: $0.235>$ Ireland: $0.123, \Delta \mathrm{t}=5.447, \mathrm{p}<0.001$ ). Although the difference between the two countries is statistically significant, the direction of the hypothesis is opposite. Therefore, $\mathrm{H}_{6 \mathrm{a}}$ was not supported. Furthermore, the relationship between perceived ease of use and behavioral intention to use AR was not stronger in South Korea's feminine culture than in Ireland's masculine culture. The path for Ireland had a stronger effect on behavioral intentions compared to South Korea (South Korea: 0.105 < Ireland: $0.401, \Delta \mathrm{t}=-17.386, \mathrm{p}<0.001)$. Although the difference between the two countries is statistically significant, the direction of the hypothesis is opposite. Therefore, $\mathrm{H}_{7}$ a was not supported.

Nevertheless, the path between perceived enjoyment and behavioral intention to use AR was stronger in South Korea's higher power distance culture than in Ireland's lower power distance culture. The path from perceived enjoyment to behavioral intention to use AR was significant in both countries, although it was larger for South Korea than for Ireland (South Korea: $0.336>$ Ireland: $0.235, \Delta \mathrm{t}=$ $5.525, \mathrm{p}<0.001$ ), thereby supporting $\mathrm{H}_{8 \mathrm{a}}$. Finally, the effect of the three cultural difference dimensions (power distance, individualism/collectivism and uncertainty avoidance) on the path between social influence and behavioral intention to use AR was hypothesized in $\mathrm{H}_{9 \mathrm{a}}$. The relationship between social influence and behavioral intention to use AR was significant in both countries, although it was larger for South Korea than for Ireland (South Korea: $0.223>$ Ireland: 0.149, $\Delta t=9.635, p<0.001$ ), thereby supporting $\mathrm{H}_{9 \mathrm{a}}$.

\section{Cross-validation}

Even though our proposed research model has a good explanation of the data, we knew that the results could be specific to those samples. Therefore, a cross-validity study used to test for the predictive validity of the model (Woodside et al., 1989). The cross-validation method uses the model developed from the measures for one country to predict the measures with the other country and examines the correlation of the measures between the respective models. For the correlation between the model for South Korea and the data for Ireland, all correlations (perceived usefulness: $\gamma=0.637$, perceived ease of use: $\gamma=0.611$, perceived enjoyment: $\gamma=0.836$, behavioral intention: $\gamma=0.721$ ) were statistically significant $(\mathrm{p}<0.01)$. Also, for the correlation between the model for Ireland and the data for South Korea, all correlations (perceived usefulness: $\gamma=0.659$, perceived ease of use: $\gamma=0.591$, perceived enjoyment: $\gamma=0.716$, behavioral intention: $\gamma=0.703)$ were statistically significant $(p<0.01)$. With the exception of perceived enjoyment (model for South Korea, data for Ireland), the correlation between predicted measures and observed measures are medium high and statistically significant, indicating the validity of our results.

\section{Discussion, Implications and Limitations}

The objective of this study was to assess the impact of aesthetics of AR and perceived factors including enjoyment on behavioral intention to use AR at cultural heritage tourism sites as well as investigate the influence of cultural differences between South Korea and Ireland on these causal sequences. The results showed that the aesthetic features - rather than utilitarian components - of AR have the strongest influence on perceived enjoyment (i.e., perceived usefulness and ease of use). Contrary to expectations, the impact of perceived usefulness was not strong, and the impact of perceived ease of use was not weak in Ireland's masculine culture. However, as expected, the relationship between perceived enjoyment and behavioral intention to use AR was stronger in South Korea's higher power distance culture. In terms of the impact of social influence on behavioral intention to use AR, respondents in South Korea - having collectivism, higher uncertainty avoidance and a higher power distance culture - displayed stronger dependence on social influence. AR is expected to be the next big thing on the consumer market and it is crucial to consider users' cultural traits before developing 
AR strategies. Understanding cultural traits will be a critical aspect of successful future AR implementation. This study shows that there is no one-size-fits-all approach for the development of AR applications and that tourism and hospitality organizations need to be aware that different content and functionalities will appeal to different target markets. This study supports Rohm et al. (2012) who confirmed that social influence is more important in collectivist countries such as South Korea. Furthermore, this study supports a number of studies (Kelman 1958; Kelman, 1961; Srite \& Karahanna, 2006) with regard to perceived enjoyment and social influence on behavioral intentions within high power distance cultures. Consequently, this study clearly shows that users' perceived enjoyment and social influence in South Korea is extremely important, a finding that can be linked to their perception of power and relation to superiors. Again, this result provides implications for technology design and differences in demand among cultures.

\section{Theoretical contributions}

This study provides several theoretical contributions. This is a unique study exploring the underresearched topic of cultural differences within the AR cultural heritage tourism context. In general, there has been limited research on AR adoption and acceptance factors, according to tom Dieck and Jung (2015). Furthermore, there is limited AR-related research on cultural differences in the tourism and hospitality context; consequently, it has been unknown how cultural traits influence AR acceptance. This study bridged the gap addressing the aforementioned limited research. In addition, with regard to cultural differences and technology adoption, only a small number of previous studies have applied a structural equation model (e.g., Matzler et al., 2016; Srite \& Karahanna, 2006). By drawing on a structural equation model, this study empirically tested the effect of cultural differences on the causal sequence toward behavioral intention to use AR. Nevertheless, the findings showed no relationship between the impact of utilitarian components of AR and the masculinity/femininity culture types. This is partly consistent with findings from a study by Srite and Karahanna (2006) that revealed that masculinity/femininity values do not moderate the relationship between perceived usefulness and behavioral intentions. On the contrary, the importance of the hedonic component of AR and social influence were perceived differently in the Western and Eastern countries. Again, this is partly consistent with results from previous studies (e.g., Harris et al., 2005; Srite \& Karahanna, 2006; Venkatesh \& Morris, 2000). Another interesting finding is that aesthetics was found to be the strongest attribute of perceived enjoyment in both countries. This result demonstrates that the aesthetic features of AR can indeed induce hedonic perceptions. In addition, the inclusion of aesthetics added significantly to the existing pool of knowledge. In fact, previous studies that investigated this area focused solely on utilitarian components of AR, such as perceived usefulness and ease of use (e.g., Vlahakis et al., 2001), or the functional quality of AR.

\section{Managerial implications}

The first managerial implication relates to the importance of AR design. Cultural heritage tourism attractions, destination marketing managers and AR developers at cultural heritage tourism sites around the world can refer to this study's findings with regard to important areas to focus on when designing and implementing AR applications. In Eastern and Western cultures alike, the aesthetics of AR applications are crucial to ensure positive perceptions. As positive emotions lead to behavioral intentions (Su \& Hsu, 2013), tourism practitioners and application developers are advised to place importance on aesthetic design features to ensure successful implementation. Furthermore, factors such as usability, enjoyment and social influence should be considered, especially in higher power distance, uncertainty avoidance, and collectivist cultures such as South Korea. On the other hand, ease of use of AR and the provision of manuals should be the focus in lower power distance, uncertainty avoidance and individualist cultures such as Ireland. For tourism and hospitality practitioners, this study clearly shows that whatever consumer technology is being introduced, there needs to be awareness and knowledge of different cultural demands from the consumers' point of view. Usability 
is an important issue for consumer adoption of AR technology, and there needs to be a clear benefit in using AR to be accepted by hotel guests and visitors at destinations. Nonetheless, if targeting tourists from collectivist, high power distance and high uncertainty avoidance cultures, design needs to follow the rules of creating more enjoyable, fun and engaging content and functionalities that are socially accepted and recommended by peers.

\section{Limitations and Future Research}

There are a number of limitations within the present study. First, at the time of experiment, AR applications had not been sufficiently commercialized and known by many tourists. Thus, a manual about how to use the AR applications had to be produced and provided to respondents before conducting the survey. In addition, only young, highly educated people or those who were willing to learn about AR applications could participate in this survey. This makes it difficult to say if participants in this study were truly representative of each culture. Second, the majority of both samples were female, and previous studies had found that there are gender differences with regard to factors influencing technology usage intentions (Padilla-Meléndez et al., 2013). Therefore, future research is advised to explore gender differences as part of a study on AR cultural differences in order to fully understand the acceptance of AR among different countries and cultures. Third, this study investigated different AR applications in each country: "Dublin AR" in Ireland and "Deoksugung, in my hand" in South Korea. Although the contents differed according to the different purposes of the AR application and the different cultural contexts, the structure, design, and interface of the AR applications used for this study shared very similar functionality. Thus, it is a possibility that aesthetics and functional differences among the two AR applications are reflected in the results. Consequently, further studies should include tourists from different cultures while using exactly the same AR application to show the true impact of cultural differences on behavioral intention to use AR. Furthermore, researchers should develop a universal model of AR acceptance based on cross-cultural differences.

\section{References}

Ahuja, M. K. and Thatcher, J. B. (2005), "Moving beyond intentions and toward the theory of trying: Effects of work environments and gender on post-adoption information technology use", $M I S$ Quarterly, Vol. 29 No. 3, pp. 427-459.

Augment. (2016), “Augmented reality applocations for hoteliers", available at: http://www.augment.com/blog/augmented-reality-applications-for-hoteliers/ (accessed 8 May 2017).

Ayeh, J. K., Au, N. and Law, R. (2013), "Predicting the intention to use consumer-generated media for travel planning", Tourism Management, Vol. 35, pp. 132-143.

Azuma, R. T. (1997), “A survey of augmented reality”, Presence, Vol. 6 No. 4, pp. 355-385.

Baird, I. S. and Thomas, H. (1985), "Toward a contingency model of strategic risk taking", Academy of Management Review, Vol. 10 No. 2, pp. 230-243.

Balog, A. and Pribeanu, C. (2010), "The role of perceived enjoyment in the students' acceptance of an augmented reality teaching platform: A structural equation modelling approach", Studies in Informatics and Control, Vol. 19 No. 3, pp. 319-330.

Bhattacherjee, A. and Sanford, C. (2006), "Influence processes for information technology acceptance: an elaboration likelihood model", MIS quarterly, Vol. 30 No. 4, pp. 805-825.

Billinghurst, M., Kato, H. and Poupyrev, I. (2001), "The magicbook-moving seamlessly between reality and virtuality", Computer Graphics and Applications, IEEE, Vol. 21 No. 3, pp. 6-8.

Bujak, K. R., Radu, I., Catrambone, R., MacIntyre, B., Zheng, R. and Golubski, G. (2013), "A psychological perspective on augmented reality in the mathematics classroom", Computers and Education, Vol. 68, pp. 536-544.

Campbell, D. T. and D. W. Fiske (1959), "Convergent and discriminant validation by the multitraitmultimethod matrix", Psychological Bulletin, Vol.56 No.2, pp. 81-105. 
Chin, W.W. (1998), The partial least squares approach for structural equation modelling. In George A. Marcoulides (Ed.), Modern Methods for Business Research, Lawrence Erlbaum Associates.

Cho, C. H. and Cheon, H. J. (2005), "Cross-cultural comparisons of interactivity on corporate web sites: the United States, the United Kingdom, Japan, and South Korea”, Journal of advertising, Vol. 34 No. 2, pp. 99-115.

Chuah, S. H. W., Rauschnabel, P. A., Krey, N., Nguyen, B., Ramayah, T. and Lade, S. (2016), "Wearable technologies: The role of usefulness and visibility in smartwatch adoption", Computers in Human Behavior, Vol. 65, pp. 276-284.

Chun, H., Lee, H. and Kim, D. (2012), "The integrated model of smartphone adoption: Hedonic and utilitarian value perceptions of smartphones among Korean college students", Cyberpsychology, Behavior, and Social Networking, Vol. 15 No. 9, pp. 473-479.

Chung, N., Koo, C. and Kim, J. K. (2014), "Extrinsic and intrinsic motivation for using a booth recommender system service on exhibition attendees' unplanned visit behavior", Computers in Human Behavior, Vol. 30, pp. 59-68.

Cyr, D., Head, M. and Ivanov, A. (2006), "Design aesthetics leading to m-loyalty in mobile commerce", Information and Management, Vol. 43 No. 8, pp. 950-963.

Davis, F. D. (1989), "Perceived usefulness, perceived ease of use, and user acceptance of information Technology", MIS quarterly, Vol. 13 No. 3, pp. 319-340.

Deci, E. L. (1975), Intrinsic motivation, Plenum Press, New York.

Deci, E. L. and Ryan, R. M. (1987), "The support of autonomy and the control of behavior", Journal of personality and social psychology, Vol. 53 No. 6, pp. 1024-1037.

Di Serio, Á., Ibáñez, M. B. and Kloos, C. D. (2013), "Impact of an augmented reality system on students' motivation for a visual art course", Computers and Education, Vol. 68, pp. 586-596.

Evaristo, J. R. and Karahanna, E. (1998), "The impact of mental workload in the evaluation of innovations", Information Systems Innovation and Diffusion: Issues and Directions, pp. 48-70.

Fornell C. and Larcker D. (1981), "Evaluating structural equation models with unobservable variables and measurement error", Journal of Marketing Research, Vol.18 No.1, pp.39-50.

Gao, L. and Bai, X. (2014), "A unified perspective on the factors influencing consumer acceptance of internet of things technology", Asia Pacific Journal of Marketing and Logistics, Vol. 26 No. 2, pp. 211-231.

Han, J., Hyun, E., Kim, M., Cho, H., Kanda, T. and Nomura, T. (2009), “The cross-cultural acceptance of tutoring robots with augmented reality services", JDCTA, Vol. 3 No. 2, pp. 95-102.

Han, D., tom Dieck, M. C. and Jung, T. (2017), "User experience model for augmented reality applications in the urban heritage tourism", Journal of Heritage Tourism. DOI: 10.1080/1743873X.2016.1251931

Harris, P., Rettie, R. and Cheung, C. K. (2005), "Adoption and usage of m-commerce: a cross-cultural comparison of Hong Kong and the United Kingdom", Journal of Electronic Commerce Research, Vol. 6 No. 3, pp. 210-224.

Haugstvedt, A. C. and Krogstie, J. (2012), "Mobile augmented reality for cultural heritage: A technology acceptance study", In The Mixed and Augmented Reality (ISMAR), 2012 IEEE International Symposium on (pp. 247-255). IEEE, Atlanta.

Hofstede, G. (1980), "Culture and organizations", International Studies of Management and Organization, pp. 15-41.

Hofstede, G. (1984), Culture's consequences: International differences in work-related values, $5^{\text {th }}$ ed, Sage Publications, California.

Hofstede, G. (2000), Culture's consequences: Comparing values, behaviors, institutions, and organizations across nations, Sage Publications, London.

Hofstede, G. and Bond, M. H. (1988), "The Confucius connection: From cultural roots to economic growth", Organizational dynamics, Vol. 16 No. 4, pp. 5-21. 
Hofstede, G. H. (Ed.). (1998), Masculinity and femininity: The taboo dimension of national cultures, $3^{\text {rd }}$ ed, Sage Publications, California.

Hui, C. H. and Triandis, H. C. (1986), "Individualism-collectivism a study of cross-cultural researchers", Journal of cross-cultural psychology, Vol. 17 No. 2, pp. 225-248.

Jung, T., Chung, N., and Leue, M. C. (2015), "The determinants of recommendations to use augmented reality technologies: The case of a Korean theme park", Tourism management, Vol. 49, pp. 7586.

Jung, T. and tom Dieck, M. C. (2017), "Augmented reality, virtual reality and 3D printing for the cocreation of value for the visitor experience at cultural heritage places", Journal of Place Management and Development. Vol. 10 No. 2, pp. 140-151.

Kelman, H. C. (1958), "Compliance, identification, and internalization: Three processes of attitude change", Journal of conflict resolution, pp. 51-60.

Kelman, H. C. (1961), "Processes of opinion change", Public Opinion Quarterly, Vol. 25 No. 1, pp. 57-78.

Kim, H. B., Kim, T. T. and Shin, S. W. (2009), "Modeling roles of subjective norms and eTrust in customers' acceptance of airline B2C eCommerce websites", Tourism Management, Vol. 30 No. 2, pp. 266-277.

Kim, Y., Sohn, D. and Choi, S. M. (2011), "Cultural difference in motivations for using social network sites: A comparative study of American and Korean college students", Computers in Human Behavior, Vol. 27 No. 1, pp. 365-372.

Kounavis, C. D., Kasimati, A. E., Zamani, E. D. and Giaglis, G. M. (2012), "Enhancing the tourism experience through mobile augmented reality: Challenges and prospects", International Journal of Engineering Business Management, Vol. 4 No. 10, pp. 1-6.

Landauer, M., Haider, W. and Pröbstl-Haider, U. (2013), "The influence of culture on climate change adaptation strategies: preferences of cross-country skiers in Austria and Finland", Journal of Travel Research, Vol. 53 No. 1, pp. 96-110.

Lee, L. Y. S. (2013), "Hospitality industry web-based self-service technology adoption model: A cross-cultural perspective”, Journal of Hospitality \& Tourism Research, Vol. 40 No. 2, pp. 162197.

Lee, K. C. and Chung, N. (2009), "Understanding factors affecting trust in and satisfaction with mobile banking in Korea: A modified DeLone and McLean's model perspective", Interacting with computers, Vol. 21 No. 5, pp. 385-392.

Lee, S. G., Trimi, S. and Kim, C. (2013), "The impact of cultural differences on technology adoption. Journal of World Business", Vol. 48 No. 1, pp. 20-29.

Li, M. (2012), "Cross-cultural tourist research: A meta-analysis", Journal of Hospitality \& Tourism Research, Vol. 38 No. 1, pp. 40-77.

Li, Y. M. and Yeh, Y. S. (2010), "Increasing trust in mobile commerce through design aesthetics", Computers in Human Behavior, Vol. 26 No. 4, pp. 673-684.

Loureiro, S. M. C. (2014), "The role of the rural tourism experience economy in place attachment and behavioral intentions", International Journal of Hospitality Management, Vol. 40, pp. 1-9.

Lu, H.-P. and Su, P.Y.-J. (2009), "Factors affecting purchase intention on mobile shopping web sites", Internet Research, Vol. 19 No. 4, pp. 442-458.

MacDonald, C. M. and Atwood, M. E. (2014), "What does it mean for a system to be useful?: An exploratory study of usefulness", Paper presented at the 2014 conference on Designing interactive systems, ACM.

Marimon, D., Sarasua, C., Carrasco, P., Álvarez, R., Montesa, J., Adamek, T. ... and Gascó, P. (2010), "MobiAR: tourist experiences through mobile augmented reality", Paper presented at Telefonica Research and Development, Barcelona, Spain. 
Matzler, K., Strobl, A., Stokburger-Sauer, N., Bobovnicky, A. and Bauer, F. (2016), "Brand personality and culture: The role of cultural differences on the impact of brand personality perceptions on tourists' visit intentions", Tourism Management, Vol. 52, pp. 507-520.

McCoy, S., Galletta, D. F. and King, W. R. (2007), “Applying TAM across cultures: the need for caution", European Journal of Information Systems, Vol. 16, pp. 81-90.

Moorhouse, N., tom Dieck, M.C. and Jung, T. (2017), "Augmented reality to enhance the learning experience in cultural heritage tourism: An experiential learning cycle perspective", e-Review of Tourism Research, Vol. 8, pp. 1-5.

Mulloni, A., Dünser, A. and Schmalstieg, D. (2010, September), “Zooming interfaces for augmented reality browsers", Paper presented at the 12th international conference on Human computer interaction with mobile devices and services, September, ACM.

Nunnally, J. C. (1967), Psychometric theory. New York: McGraw-Hill.

Oh, H., Fiore, A. M. and Jeoung, M. (2007), "Measuring experience economy concepts: tourism applications", Journal of Travel Research, Vol. 46 No. 2, pp. 119-132.

Padilla-Meléndez, A., Del Aguila-Obra, A. R. and Garrido-Moreno, A. (2013), "Perceived playfulness, gender differences and technology acceptance model in a blended learning scenario", Computers \& Education, Vol. 63, pp. 306-317.

Pine, B. J. and Gilmore, J. H. (1998), "Welcome to the experience economy", Harvard business review, Vol. 76, pp. 97-105.

Podsakoff, P. M., MacKenzie, S. B., Lee, J.-Y., and Podsakoff, N. P. (2003), "Common method biases in behavioral research: A critical review of the literature and recommended remedies," Journal of Applied Psychology, Vol.88 No.5, pp. 879-903.

Portalés, C., Lerma, J. L. and Pérez, C. (2009), "Photogrammetry and augmented reality for cultural heritage applications", The Photogrammetric Record, Vol. 24 No. 128, pp. 316-331.

Quintal, V. A., Lee, J. A. and Soutar, G. N. (2010), "Risk, uncertainty and the theory of planned behavior: A tourism example", Tourism Management, Vol. 31 No. 6, pp. 797-805.

Rauschnabel, P. A., Brem, A. and Ivens, B. S. (2015), "Who will buy smart glasses? Empirical results of two pre-market-entry studies on the role of personality in individual awareness and intended adoption of Google Glass wearables", Computers in Human Behavior, Vol. 49, pp. 635-647.

Rauschnabel, P. A., Rossmann, A. and tom Dieck, M.C. (2017), "An Adoption Framework for Mobile Augmented Reality Games: The Case of Pokémon Go", Computers in Human Behavior, Vol. 76, pp. 276-286.

Richter, F. (2013, August 27), "The United States ranks 13th in smartphone penetration", available at http://www.statista.com/chart/1405/the-united-states-ranks-13th-in-smartphone-penetration/ (accessed January 22, 2015).

Rohm, A. J., Gao, T. T., Sultan, F. and Pagani, M. (2012), "Brand in the hand: A cross-market investigation of consumer acceptance of mobile marketing", Business Horizons, Vol. 55 No. 5, pp. 485-493.

Sadeh, N. (2002), m-Commerce: Technologies, services, and business models, John Wiley, New York.

Sarker, S. and Wells, J. (2003), "Understanding mobile handheld device and adoption", Communications of the ACM, Vol. 46 No. 12, pp. 35-40.

Solomon, M. R. (2009), Consumer behavior: buying, having, and being, Pearson, Edinburgh.

Stanco, F., Tanasi, D., Gallo, G., Buffa, M. and Basile, B. (2012), "Augmented perception of the past. The case of hellenistic Syracuse", Journal of Multimedia, Vol. 7 No. 2, pp. 211-216.

Srite, M. and Karahanna, E. (2006), "The role of espoused national cultural values in technology acceptance", MIS quarterly, Vol. 30 No. 3, pp. 679-704.

$\mathrm{Su}$, L. and Hsu, M. K. (2013), "Service fairness, consumption emotions, satisfaction, and behavioral intentions: The experience of Chinese heritage tourists", Journal of Travel \& Tourism Marketing, Vol. 30 No. 8, pp. 786-805.

Tabachnick, B. G. and Fidell, L. S. (2007), Using multivariate statistics, 5th ed, Pearson, Boston. 
Tarhini, A., Hone, K., Liu, X. and Tarhini, T. (2017), "Examining the moderating effect of individuallevel cultural values on users' acceptance of E-learning in developing countries: A structural equation modeling of an extended technology acceptance model", Interactive Learning Environments, Vol. 25 No. 3, pp. 306-328.

tom Dieck, M. C. and Jung, T. (2015), “A theoretical model of mobile augmented reality acceptance in urban heritage tourism", Current Issues in Tourism, pp. 1-21

tom Dieck, M. C., Jung, T. and Han, D. (2016), "Mapping user requirements for the wearable smart glasses augmented reality application", Journal of Hospitality and Tourism Technology, Vol. 7 No. 3, pp. 230-253.

tom Dieck, M.C., Jung, T., Kim, W. and Moon, Y. (2017), "Hotel Guests' Social Media Acceptance in Luxury Hotels", International Journal of Contemporary Hospitality Management, Vol. 29 No. 1, pp. 530-550.

tom Dieck, M. C. and Jung, T. (2017), "Value of augmented reality at cultural heritage sites: A stakeholder approach, Journal of Destination Marketing \& Management. Vol. 6, pp. 110-117.

Triandis, H. C. (1995), Individualism \& collectivism, Westview Press, Colorado.

Tsang, N. K. F. and Ap, J. (2007), “Tourists' perceptions of relational quality service attributes: A cross-cultural study", Journal of Travel Research, Vol. 45 No. 3, pp. 355-363.

Tuominen, P. P. and Ascenção, M. P. (2016), "The hotel of tomorrow: A service design approach", Journal of Vacation Marketing, Vol. 22 No. 3, pp. 279-292.

Tussyadiah, I. P. (2013), "Toward a theoretical foundation for experience design in tourism", Journal of Travel Research, Vol. 53 No. 5, pp. 543-564.

Tussyadiah, I., Jung, T. and tom Dieck, M. C. (2017), "Embodiment of wearable augmented reality technology in tourism experiences", Journal of Travel Research doi:10.1177/0047287517709090

Tutunea, M. F. S. (2013), “Augmented reality-state of knowledge, use and experimentation”, The USV Annals of Economics and Public Administration, Vol. 13 No.2, pp. 215-227.

Vallerand, R. J. (1997), Toward a hierarchical model of intrinsic and extrinsic motivation, Academic Press, New York.

Van der Heijden, H. (2004), "User acceptance of hedonic information systems", MIS quarterly, Vol. 28 No. 4, pp. 695-704.

Venkatesh, V. (2000), "Determinants of perceived ease of use: Integrating control, intrinsic motivation, and emotion into the technology acceptance model", Information systems research, Vol. 11 No. 4, pp. 342-365.

Venkatesh, V. and Bala, H. (2008), "Technology acceptance model 3 and a research agenda on interventions", Decision Sciences, Vol. 39 No. 2, pp. 273-314.

Venkatesh, V., Morris, M. G., Davis, G. B. and Davis, F. D. (2003), "User acceptance of information technology: Toward a unified view", MIS quarterly, Vol. 27 No. 3, pp. 425-478.

Venkatesh, V. and Morris, M. G. (2000), "Why don't men ever stop to ask for directions? Gender, social influence, and their role in technology acceptance and usage behavior", MIS quarterly, Vol. 24 No. 1, pp. 115-139.

Venkatesh, V., Morris, M. G. and Ackerman, P. L. (2000), “A longitudinal field investigation of gender differences in individual technology adoption decision-making processes", Organizational behavior and human decision processes, Vol. 83 No. 1, pp. 33-60.

Vitell, S. J., Nwachukwu, S. L. and Barnes, J. H. (1993), "The effects of culture on ethical decisionmaking: An application of Hofstede's typology”, Journal of Business Ethics, Vol. 12 No. 10, pp. 753-760.

Vlahakis, V., Karigiannis, J., Tsotros, M., Gounaris, M., Almeida, L., Stricker, D. and Ioannidis, N. (2001), "Archeoguide: First results of an augmented reality, mobile computing system in cultural heritage sites". In Proceedings of the 2001 conference on Virtual reality, archeology, and cultural heritage, (pp. 131-140). Glyfada, Greece. 
Wang, D., Park, S. and Fesenmaier, D. R. (2012), "The role of smartphones in mediating the touristic experience", Journal of Travel Research, Vol. 51 No. 4, pp. 371-387.

Woodside, A. G., Frey, L. L. and Daly, R. T. (1989), "Linking service quality, customer satisfaction, and behavioral intention", Journal of health Care marketing, Vol. 9 No. 4, pp. 5-17.

Table 1.

Hofstede's cultural dimensions 


\begin{tabular}{|c|c|c|c|}
\hline \multirow{2}{*}{\multicolumn{2}{|c|}{ Definition }} & \multicolumn{2}{|c|}{ Country score (1 120) } \\
\hline & & South Korea & Ireland \\
\hline $\begin{array}{l}\text { Masculinity/ } \\
\text { Femininity }\end{array}$ & $\begin{array}{l}\text { Degree to which gender inequalities are espoused by an } \\
\text { individual. Individuals who espouse masculine values } \\
\text { emphasize work goals such as earnings, advancement, } \\
\text { competitiveness, performance and assertiveness. On the } \\
\text { other hand, individuals who espouse feminine values tend } \\
\text { to emphasize personal goals such as a friendly atmosphere, } \\
\text { comfortable work environment, quality of life, and warm } \\
\text { personal relationships. }\end{array}$ & $\begin{array}{c}39 \\
\text { (Femininity) }\end{array}$ & $\begin{array}{c}68 \\
\text { (Masculinity) }\end{array}$ \\
\hline Power Distance & $\begin{array}{l}\text { Degree to which large differentials of power and inequality } \\
\text { are accepted as normal by the individual. Power distance } \\
\text { will condition the extent to which the employee accepts that } \\
\text { his/her superiors have more power. }\end{array}$ & $\begin{array}{c}60 \\
\text { (High) }\end{array}$ & $\begin{array}{c}28 \\
\text { (Low) }\end{array}$ \\
\hline $\begin{array}{l}\text { Individualism/ } \\
\text { Collectivism }\end{array}$ & $\begin{array}{l}\text { Degree to which the individual emphasizes his/her own needs } \\
\text { as opposed to the group needs and prefer to act as an } \\
\text { individual rather than as a member of a group. }\end{array}$ & $\begin{array}{c}18 \\
\text { (Collectivism) }\end{array}$ & $\begin{array}{c}70 \\
\text { (Individualism) }\end{array}$ \\
\hline $\begin{array}{l}\text { Uncertainty } \\
\text { Avoidance }\end{array}$ & $\begin{array}{l}\text { The level of risk accepted by the individual which can be } \\
\text { gleaned by his/her emphasis own rule obedience, ritual } \\
\text { behavior and labor mobility. This dimension examines the } \\
\text { extent to which one feels threatened by ambiguous } \\
\text { situations. }\end{array}$ & $\begin{array}{c}85 \\
\text { (High) }\end{array}$ & $\begin{array}{c}35 \\
\text { (Low) }\end{array}$ \\
\hline
\end{tabular}


Table 2.

Demographic characteristics of respondents

\begin{tabular}{|c|c|c|c|c|}
\hline \multirow[b]{2}{*}{ Characteristics } & \multicolumn{2}{|c|}{ South Korea } & \multicolumn{2}{|c|}{ Ireland } \\
\hline & Frequency & $\%$ & Frequency & $\%$ \\
\hline \multicolumn{5}{|l|}{ Gender } \\
\hline male & 51 & 35.2 & 21 & 17.6 \\
\hline female & 94 & 64.8 & 98 & 82.4 \\
\hline \multicolumn{5}{|l|}{ Age } \\
\hline 19 and below & 35 & 24.1 & 84 & 70.6 \\
\hline $20-29$ & 67 & 46.2 & 26 & 21.8 \\
\hline $30-39$ & 23 & 15.9 & 6 & 5.0 \\
\hline $40-49$ & 16 & 11.0 & 3 & 2.5 \\
\hline $50-59$ & 4 & 2.8 & 0 & 0.0 \\
\hline \multicolumn{5}{|l|}{ Current educational degree } \\
\hline High school and below & 37 & 25.5 & 10 & 8.4 \\
\hline 2-year degree course (College) & 45 & 31.0 & 1 & 0.8 \\
\hline 3 or 4 year degree course (University) & 47 & 32.4 & 89 & 74.8 \\
\hline Postgraduate course and above & 16 & 11.0 & 19 & 16.0 \\
\hline \multicolumn{5}{|l|}{ Job } \\
\hline student & 87 & 60.0 & 107 & 89.9 \\
\hline administrator & 20 & 13.8 & 0 & 0.0 \\
\hline sales & 3 & 2.1 & 3 & 2.5 \\
\hline manual labor & 3 & 2.1 & 0 & 0.0 \\
\hline professional & 12 & 8.3 & 1 & .8 \\
\hline self-employed & 0 & 0.0 & 1 & .8 \\
\hline civil servants & 8 & 5.5 & 2 & 1.7 \\
\hline house wife/husband & 8 & 5.5 & 0 & 0.0 \\
\hline other & 4 & 2.8 & 5 & 4.2 \\
\hline \multicolumn{5}{|l|}{ Marital status } \\
\hline married & 34 & 23.4 & 4 & 3.4 \\
\hline single & 111 & 76.6 & 115 & 96.6 \\
\hline \multicolumn{5}{|l|}{ Have you used AR in the past? } \\
\hline YES & 48 & 33.1 & 11 & 9.2 \\
\hline NO & 97 & 66.9 & 108 & 90.8 \\
\hline Total & 145 & 100.0 & 119 & 100.0 \\
\hline
\end{tabular}


Table 3.

Factor loadings and reliability

\begin{tabular}{|c|c|c|c|c|c|c|c|c|c|c|}
\hline \multirow{2}{*}{ Constructs } & \multirow{2}{*}{ Measurement items } & \multicolumn{6}{|c|}{ Factor Loadings } & \multirow{2}{*}{$\alpha$} & \multirow{2}{*}{ CR } & \multirow{2}{*}{ AVE } \\
\hline & & (1) & (2) & (3) & (4) & (5) & (6) & & & \\
\hline \multirow{5}{*}{ (1) Aesthetics } & When I used AR app, I felt a real sense of harmony. & 0.766 & 0.274 & 0.136 & 0.130 & 0.104 & 0.166 & \multirow{5}{*}{0.915} & \multirow{5}{*}{0.937} & \multirow{5}{*}{0.749} \\
\hline & When I used AR app, just being here was very pleasant. & 0.811 & 0.257 & 0.108 & 0.216 & 0.115 & 0.209 & & & \\
\hline & When I used AR app, the setting was not bland. & 0.758 & 0.144 & 0.155 & 0.197 & 0.094 & 0.311 & & & \\
\hline & When I used AR app, the setting really showed attention to design detail. & 0.762 & 0.119 & 0.193 & 0.183 & 0.200 & 0.092 & & & \\
\hline & When I used AR app, the setting provided pleasure to my senses. & 0.759 & 0.197 & 0.159 & 0.259 & 0.178 & 0.089 & & & \\
\hline \multirow{4}{*}{$\begin{array}{l}\text { (2) Perceived } \\
\text { usefulness }\end{array}$} & Using AR app can improve my travel information gathering performance. & 0.210 & 0.735 & 0.286 & 0.191 & 0.191 & 0.184 & \multirow{4}{*}{0.923} & \multirow{4}{*}{0.946} & \multirow{4}{*}{0.814} \\
\hline & Using AR app can increase my travel information gathering productivity. & 0.270 & 0.829 & 0.122 & 0.202 & 0.147 & 0.132 & & & \\
\hline & Using AR app can increase my travel information gathering effectiveness. & 0.217 & 0.764 & 0.275 & 0.189 & 0.129 & 0.218 & & & \\
\hline & I find using AR app useful. & 0.238 & 0.788 & 0.186 & 0.200 & 0.171 & 0.140 & & & \\
\hline \multirow{4}{*}{$\begin{array}{l}\text { (3) Perceived } \\
\text { ease of use }\end{array}$} & The interaction with the AR app is clear and understandable. & 0.162 & 0.331 & 0.706 & 0.143 & 0.144 & 0.217 & \multirow{4}{*}{0.914} & \multirow{4}{*}{0.939} & \multirow{4}{*}{0.794} \\
\hline & The interaction with the AR app does not require a lot of effort. & 0.171 & 0.162 & 0.837 & 0.185 & 0.094 & 0.124 & & & \\
\hline & I find the AR app easy to me. & 0.117 & 0.169 & 0.841 & 0.226 & 0.080 & 0.198 & & & \\
\hline & I find it easy to access the desired information through the AR app. & 0.241 & 0.179 & 0.738 & 0.321 & 0.157 & 0.164 & & & \\
\hline \multirow{4}{*}{$\begin{array}{l}\text { (4) Perceived } \\
\text { enjoyment }\end{array}$} & I have fun to access information through interacting with the AR app. & 0.272 & 0.361 & 0.320 & 0.667 & 0.162 & 0.199 & \multirow{4}{*}{0.933} & \multirow{4}{*}{0.953} & \multirow{4}{*}{0.834} \\
\hline & Using the AR app brings me lots of enjoyment. & 0.296 & 0.218 & 0.221 & 0.806 & 0.187 & 0.134 & & & \\
\hline & I enjoy using the AR app. & 0.285 & 0.240 & 0.297 & 0.762 & 0.164 & 0.204 & & & \\
\hline & Using the AR app does not bore me. & 0.279 & 0.184 & 0.269 & 0.712 & 0.134 & 0.286 & & & \\
\hline \multirow{3}{*}{$\begin{array}{l}\text { (5) Social } \\
\text { influence }\end{array}$} & $\begin{array}{l}\text { People who influence my behavior think that I should use the AR app } \\
\text { while visiting A*. }\end{array}$ & 0.035 & 0.310 & -0.030 & 0.166 & 0.733 & 0.213 & \multirow{3}{*}{0.835} & \multirow{3}{*}{0.891} & \multirow{3}{*}{0.673} \\
\hline & $\begin{array}{l}\text { People who are important to me think that I should use the AR app while } \\
\text { visiting A*. }\end{array}$ & 0.112 & 0.282 & -0.080 & 0.125 & 0.778 & 0.244 & & & \\
\hline & $\begin{array}{l}\text { The Culture Heritage Administration has been helpful in enabling me to } \\
\text { use the AR app. }\end{array}$ & 0.217 & 0.064 & 0.282 & 0.072 & 0.822 & 0.015 & & & \\
\hline \multirow{4}{*}{$\begin{array}{c}\text { (6) Behavioral } \\
\text { intention to use } \\
\text { AR }\end{array}$} & In general, A has supported the use of the AR app. & 0.232 & -0.027 & 0.314 & 0.133 & 0.699 & 0.066 & \multirow{4}{*}{0.971} & \multirow{4}{*}{0.981} & \multirow{4}{*}{0.945} \\
\hline & I intend to use the AR app in the future. & 0.310 & 0.250 & 0.291 & 0.215 & 0.190 & 0.775 & & & \\
\hline & I predict I will use the AR in the future. & 0.269 & 0.242 & 0.260 & 0.236 & 0.215 & 0.794 & & & \\
\hline & I plan to use the $A R$ in the future. & 0.309 & 0.234 & 0.264 & 0.280 & 0.226 & 0.771 & & & \\
\hline
\end{tabular}


Table 4.

Correlation and discriminant validity

\begin{tabular}{|c|c|c|c|c|c|c|c|c|c|c|c|}
\hline & \multirow{2}{*}{ Model and Constructs } & \multicolumn{6}{|c|}{ Correlation of constructs } & \multirow{2}{*}{ Mean } & \multirow{2}{*}{ S.D } & \multirow{2}{*}{ Skewness } & \multirow{2}{*}{ Kurtosis } \\
\hline & & (1) & $(2)$ & (3) & (4) & (5) & (6) & & & & \\
\hline \multirow{6}{*}{$\begin{array}{l}\text { Overall } \\
\text { country }\end{array}$} & (1) Aesthetics & 0.865 & & & & & \multirow[b]{6}{*}{0.972} & 5.247 & 1.233 & -0.604 & 0.129 \\
\hline & (2) Perceived usefulness & 0.579 & 0.902 & & & & & 5.528 & 1.264 & -0.951 & 0.815 \\
\hline & (3) Perceived ease of use & 0.508 & 0.565 & 0.891 & & & & 5.514 & 1.213 & -0.691 & -0.143 \\
\hline & (4) Perceived enjoyment & 0.649 & 0.640 & 0.657 & 0.913 & & & 5.372 & 1.298 & -0.791 & 0.449 \\
\hline & (5) Social influence & 0.447 & 0.475 & 0.406 & 0.477 & 0.820 & & 4.717 & 1.296 & -0.225 & -0.243 \\
\hline & (6) Behavioral intention to use $A R$ & 0.624 & 0.612 & 0.602 & 0.671 & 0.512 & & 5.572 & 1.389 & -1.057 & 0.862 \\
\hline \multirow{6}{*}{ South Korea } & (1) Aesthetics & 0.876 & & & & & \multirow[b]{6}{*}{0.976} & 5.508 & 1.183 & -1.049 & 1.204 \\
\hline & (2) Perceived usefulness & 0.600 & 0.928 & & & & & 5.703 & 1.187 & -1.295 & 1.954 \\
\hline & (3) Perceived ease of use & 0.540 & 0.577 & 0.880 & & & & 5.381 & 1.216 & -0.688 & 0.023 \\
\hline & (4) Perceived enjoyment & 0.657 & 0.739 & 0.621 & 0.904 & & & 5.372 & 1.202 & -0.754 & 0.740 \\
\hline & (5) Social influence & 0.442 & 0.483 & 0.333 & 0.509 & 0.837 & & 4.683 & 1.349 & -0.282 & -0.335 \\
\hline & (6) Behavioral intention to use $\mathrm{AR}$ & 0.611 & 0.654 & 0.520 & 0.689 & 0.524 & & 5.655 & 1.293 & -1.371 & 2.330 \\
\hline \multirow{6}{*}{ Ireland } & (1) Aesthetics & $\mathbf{0 . 8 5 0}$ & & & & & \multirow[b]{6}{*}{0.968} & 4.929 & 1.224 & -0.174 & -0.110 \\
\hline & (2) Perceived usefulness & 0.530 & 0.879 & & & & & 5.315 & 1.325 & -0.618 & 0.179 \\
\hline & (3) Perceived ease of use & 0.568 & 0.603 & 0.908 & & & & 5.676 & 1.194 & -0.723 & -0.331 \\
\hline & (4) Perceived enjoyment & 0.678 & 0.558 & 0.701 & 0.923 & & & 5.372 & 1.411 & -0.815 & 0.171 \\
\hline & (5) Social influence & 0.506 & 0.484 & 0.512 & 0.450 & 0.798 & & 4.758 & 1.234 & -0.117 & -0.129 \\
\hline & (6) Behavioral intention to use AR & 0.641 & 0.566 & 0.717 & 0.654 & 0.508 & & 5.471 & 1.497 & -0.765 & -0.167 \\
\hline
\end{tabular}

Note: Diagonal elements in the "correlation of constructs" matrix are the square root of the average variance extracted (AVE). For adequate discriminant validity, the diagonal elements should be greater than the corresponding off-diagonal elements. All correlations are statistically significant $(\mathrm{p}<0.01)$ 
Table 5. Tests of the hypotheses

(a) Main effects: Standardized structural estimates of overall country (South Korea and Ireland)

\begin{tabular}{lllcc}
\hline & & Path & Estimates \\
\hline $\mathrm{H}_{1}$ & Aesthetics & $\rightarrow$ & Perceived usefulness & 0.393 \\
$\mathrm{H}_{2}$ & Aesthetics & $\rightarrow$ & Perceived ease of use & 0.140 \\
$\mathrm{H}_{3}$ & Aesthetics & $\rightarrow$ & Perceived enjoyment & 0.649 \\
$\mathrm{H}_{4}$ & Perceived ease of use & $\rightarrow$ & Perceived usefulness & 0.368 \\
$\mathrm{H}_{5}$ & Perceived enjoyment & $\rightarrow$ & Perceived ease of use & 0.566 \\
$\mathrm{H}_{6}$ & Perceived usefulness & $\rightarrow$ & Behavioural intention to use AR & 0.209 \\
$\mathrm{H}_{7}$ & Perceived ease of use & $\rightarrow$ & Behavioural intention to use AR & 0.202 \\
$\mathrm{H}_{8}$ & Perceived enjoyment & $\rightarrow$ & Behavioural intention to use AR & 0.319 \\
$\mathrm{H}_{9}$ & Social influence & Behavioural intention to use AR & 0.179 \\
$\mathbf{R}^{2}$ & & Perceived usefulness & $0.436(43.6 \%)$ \\
\multicolumn{5}{r}{} \\
& Perceived ease of use & $0.443(44.3 \%)$ \\
& Perceived enjoyment & $0.421(42.1 \%)$ \\
\end{tabular}

(b) Moderating effects: Comparison of the path coefficients between South Korea and Ireland

\begin{tabular}{|c|c|c|c|c|c|c|c|c|c|}
\hline & & & & & & & & Results (Sout & a PersI \\
\hline & & Path & & Korea & $\begin{array}{l}\text { Ireland } \\
\text { (b) }\end{array}$ & $\begin{array}{c}\text { t-value } \\
\text { (a-b) }\end{array}$ & Femininity & High & Collect \\
\hline $\mathrm{H}_{6 \mathrm{a}}$ & $\begin{array}{l}\text { Perceived } \\
\text { usefulness }\end{array}$ & $\rightarrow$ & $\begin{array}{l}\text { Behavioral intention } \\
\text { to use } \mathrm{AR}\end{array}$ & 0.235 & 0.123 & $5.447^{* * *}$ & Not supported & - & \\
\hline $\mathrm{H}_{7 \mathrm{a}}$ & $\begin{array}{l}\text { Perceived } \\
\text { ease of use }\end{array}$ & $\rightarrow$ & $\begin{array}{l}\text { Behavioral intention } \\
\text { to use } \mathrm{AR}\end{array}$ & 0.105 & 0.401 & $-17.386^{* * *}$ & Not supported & - & \\
\hline $\mathrm{H}_{8 \mathrm{a}}$ & $\begin{array}{l}\text { Perceived } \\
\text { enjoyment }\end{array}$ & $\rightarrow$ & $\begin{array}{c}\text { Behavioral intention } \\
\text { to use AR }\end{array}$ & 0.336 & 0.235 & $5.525^{* * *}$ & - & Supported & \\
\hline $\mathrm{H}_{9 \mathrm{a}}$ & $\begin{array}{l}\text { Social } \\
\text { influence }\end{array}$ & $\rightarrow$ & $\begin{array}{l}\text { Behavioral intention } \\
\text { to use } \mathrm{AR}\end{array}$ & 0.223 & 0.149 & $9.635^{* * *}$ & - & Supported & Supp \\
\hline
\end{tabular}

Note: Multi-group analysis equation suggested by Chin (1998) as follows:

$t_{i j}=\frac{p_{1}-p_{2}}{\sqrt{\frac{\left(n_{1}-1\right) \times S E_{1}^{2}+\left(n_{2}-1\right) \times S E_{2}^{2}}{n_{1}+n_{2}-2} \times \sqrt{\frac{1}{n_{1}}+\frac{1}{n_{2}}}}}$

where

$p_{i}$ : path coefficient in structural model of culture $_{i}$;

$n_{j}$ : sample size of dataset for culture $i$;

$S E_{i}:$ standard error of path in structural model for culture $i$;

$t_{i j}: t$ statistic with $n_{1}+n_{2}-2$ degrees of freedom;

$i$ : $1=$ South Korea and $2=$ Ireland

${ }^{* * *} \mathrm{p}<0.001$ 

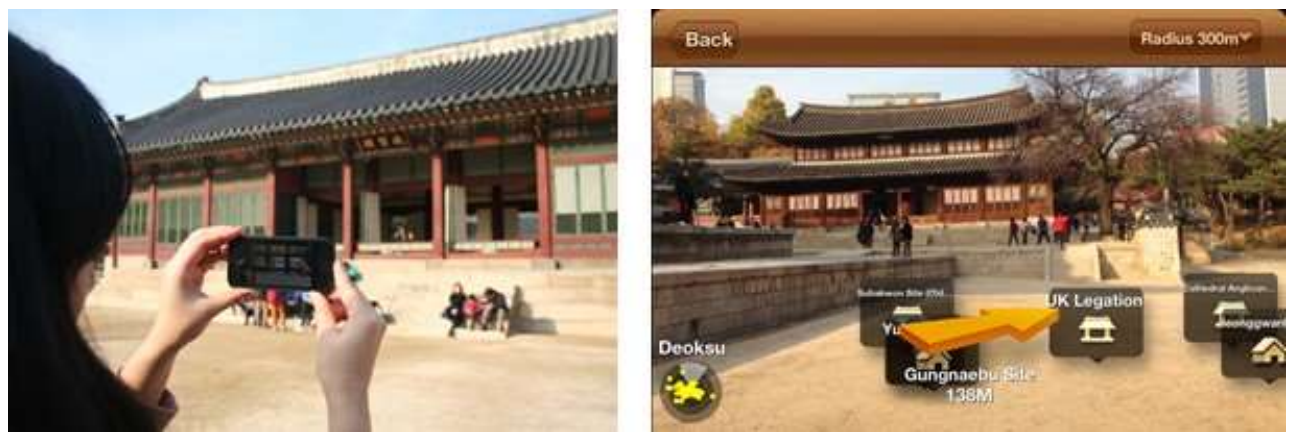

(A) Mobile AR in Deoksugung Palace (Seoul, South Korea)
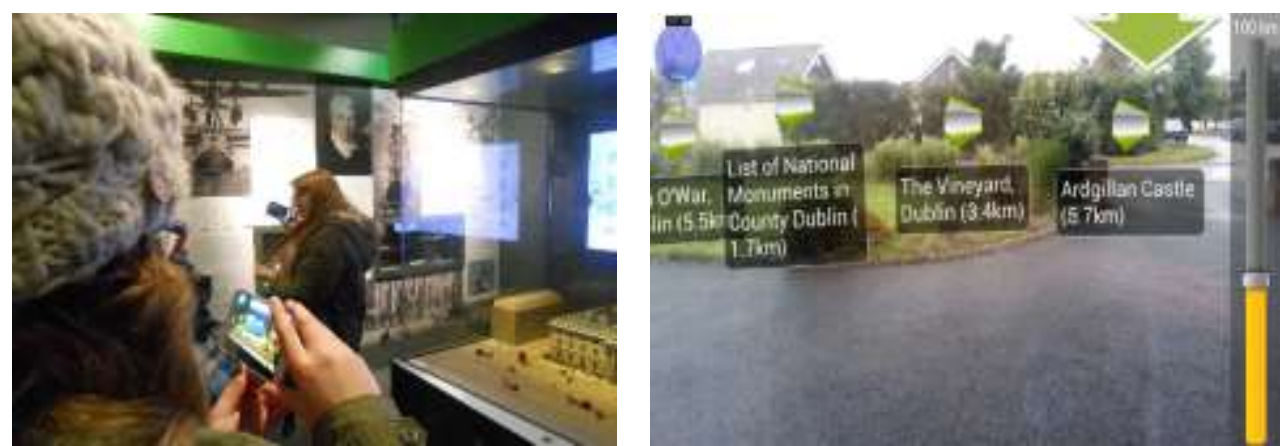

(B) Mobile AR in An Post Museum (Dublin, Ireland)

Figure 1. Snapshots of AR 


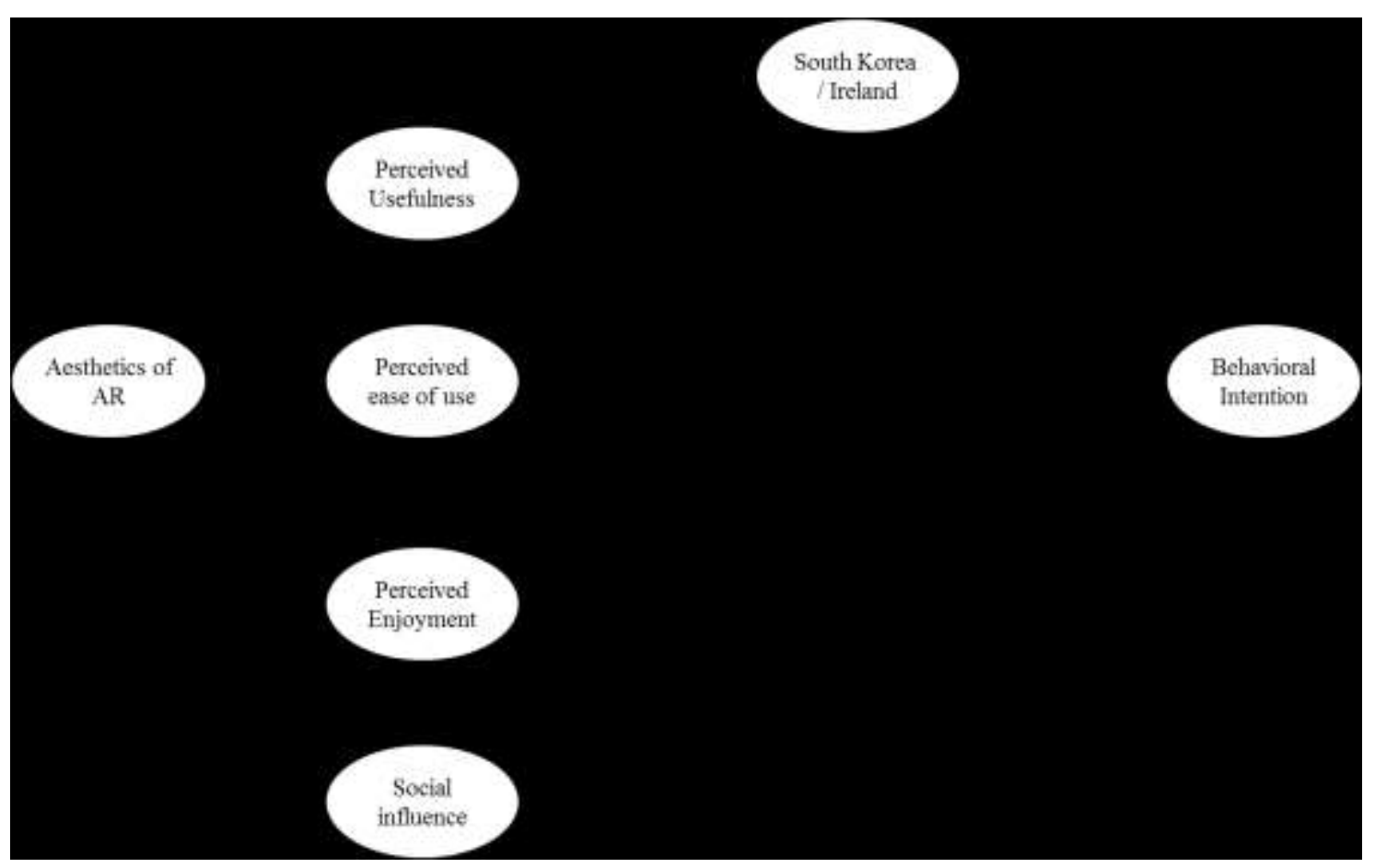

Figure 2. Proposed model 